\title{
Bacteriophage-encoded shiga toxin gene in atypical bacterial host
}

\author{
Veronica Casas ${ }^{1,2^{*}}$, Gerico Sobrepeña ${ }^{1,2}$, Beltran Rodriguez-Mueller ${ }^{1,2}$, Justine AhTye ${ }^{1,2}$ and Stanley R Maloy ${ }^{1,2}$
}

\begin{abstract}
Background: Contamination from fecal bacteria in recreational waters is a major health concern since bacteria capable of causing human disease can be found in animal feces. The Dog Beach area of Ocean Beach in San Diego, California is a beach prone to closures due to high levels of fecal indicator bacteria (FIB). A potential source of these FIB could be the canine feces left behind by owners who do not clean up after their pets. We tested this hypothesis by screening the DNA isolated from canine feces for the bacteriophage-encoded stx gene normally found in the virulent strains of the fecal bacterium Escherichia coli.

Results: Twenty canine fecal samples were collected, processed for total and bacterial fraction DNA, and screened by PCR for the stx gene. The stx gene was detected in the total and bacterial fraction DNA of one fecal sample. Bacterial isolates were then cultivated from the stx-positive fecal sample. Eighty nine of these canine fecal bacterial isolates were screened by PCR for the stx gene. The stx gene was detected in five of these isolates. Sequencing and phylogenetic analyses of $16 \mathrm{~S}$ rRNA gene PCR products from the canine fecal bacterial isolates indicated that they were Enterococcus and not E. coli.

Conclusions: The bacteriophage-encoded stx gene was found in multiple species of bacteria cultivated from canine fecal samples gathered at the shoreline of the Dog Beach area of Ocean Beach in San Diego, California. The canine fecal bacteria carrying the stx gene were not the typical $E$. coli host and were instead identified through phylogenetic analyses as Enterococcus. This suggests a large degree of horizontal gene transfer of exotoxin genes in recreational waters.
\end{abstract}

\section{Background}

Each year millions of people flock to the beaches of San Diego County for fun in the sun, sand, and surf. Monitoring water quality at these beaches is therefore extremely important to limit the possibility of illness from contact with these recreational waterways. Through San Diego County's Department of Health (DEH), the Ocean and Bay Recreational Water Program (OBRWP) is responsible for monitoring the water quality of San Diego's recreational waterways [1]. Most beaches in San Diego County are relatively clean, with little to no advisories or beach closures, but there are also areas prone to advisories and/ or beach closures because of known sources of pollution $[1,2]$. Posted warning signs, a daily water quality report hotline, and an internet podcast are some of the ways the

\footnotetext{
* Correspondence: casas.v@gmail.com

'San Diego State University 5500 Campanile Drive San Diego, California 92182-4614 USA

Full list of author information is available at the end of the article
}

OBRWP informs the public about general advisories or beach closures they have issued as a result of elevated bacterial levels in the water [1]. Typical sources of bacterial contamination at San Diego County beaches include urban runoff from storm drains and rivers, animal waste, human activities, and sewage.

Contamination from human and animal feces is of particular concern because infectious disease agents like bacteria, viruses, and protozoa are shed in the feces of infected individuals [3]. Vibrio cholera (cholera), Salmonella spp. (typhoid fever, gastroenteritis), and Shigella spp. (shigellosis) are bacteria found in feces and cause gastrointestinal disease [3]. Some pathogenic viruses that can be transmitted through use of recreational waterways include enteroviruses, hepatitis A viruses (HAV), polioviruses, coxsackie viruses, echoviruses, rotaviruses, and Norwalk viruses [4-9]. They cause a broad range of disease, not necessarily gut related, from hepatitis to polio to acute viral gastroenteritis [5,9]. Cryptosporidium, Giardia, and
Ciomed Central

() 2011 Casas et al; licensee BioMed Central Ltd. This is an Open Access article distributed under the terms of the Creative Commons Attribution License (http://creativecommons.org/licenses/by/2.0), which permits unrestricted use, distribution, and reproduction in any medium, provided the original work is properly cited. 
Entamoeba are common protozoan pathogens that cause cryptosporidiosis, giardiasis, and amoebic dysentery, respectively [3,4,9-13].

Though these organisms are common sources of waterborne diseases, their presence in these waters is not easily determined. As a result, presence of fecal indicator organisms has been accepted as the factor in determining water quality. Ideally, fecal indicator organisms would be good predictors of fecal contamination, and therefore good predictors of the potential for human illness. These fecal indicator organisms would be present whenever the pathogens were present, would survive in the environment as long as the pathogen was present, and would be easily detectable and cultivable from environmental samples [3]. Unfortunately, the relationship between presence of fecal indicator organisms, bacterial and viral pathogens, and actual fecal contamination is poorly understood. This leaves public health agencies at a disadvantage in determining the potential risk to the public's health when using recreational waterways.

The various San Diego County water quality monitoring laboratories currently use culturing assays (membrane filtration, multiple-tube fermentation, Colilert $18^{\circledR}$, Enterolert ${ }^{\mathbb{R}}$ ) to assess presence of fecal indicator organismsnamely coliforms $[1,14]$. These assays take advantage of metabolic and enzymatic properties common to coliform bacteria [3]. Many studies have been performed to evaluate if fecal indicator organisms serve as a good proxy for monitoring water quality. Comparing cultivation tests for coliforms to molecular tests for other pathogenic bacteria and viruses, the studies showed mixed results-mostly indicating that relationships depend upon the water type, exposed population, and weather conditions (see [15] for a review) [7,15-19].

It is important to be able to have a broader view of the bacterial and viral community present in recreational waters because of their potential to cause human disease. This environment may provide selection for new virulence traits that could be missed by current methods. One mechanism for acquiring new virulence traits is through horizontal gene transfer (HGT). Bacteriophage are common mediators of this genetic exchange and they often carry genes that code for virulence factors. Since the discovery that phage $\beta$ from Corynebacteria diphtheria carried the gene for diphtheria toxin and was responsible for the virulence traits of $C$. diphtheria, many more bacteriophage-encoded virulence genes have been discovered [20,21]. Some of these include the shiga toxin (stx) gene of Escherichia coli O157:H7 species, the cholera toxin gene (ctx) carried by $\operatorname{ctx} \varphi$ of Vibrio cholera, and the Staphylococcus enterotoxin A (sea) gene of Staphylococcus aureus [22-24]. Considering the high concentrations of bacteriophage and bacteria in the ocean, transduction frequencies in the World's oceans has been estimated to be as high as 20 million billion transduction events per second [25]. It is therefore important to understand the interactions between bacteria and bacteriophage in recreational waters and the potential for evolution of novel pathogens within these environments, to be able to better understand the risk to the public's health when using these waters.

\section{Materials and Methods}

\section{Canine feces sampling strategy}

Twenty canine fecal samples were gathered at the water's edge at the Ocean Beach Dog Beach in San Diego, California (Figure 1). The fecal samples were identified visually in the sand and gathered carefully with gloved hands using new disposable sandwich bags. The samples varied in size, color, consistency, and dampness. Samples were gathered and immediately returned to the lab for processing.

\section{Extraction of DNA from canine fecal samples}

Total DNA was extracted from $1.0 \mathrm{~g}$ canine fecal samples using the MoBio UltraClean Soil DNA kit (Carlsbad, CA) maximum yield protocol. A previously described method was modified and used to extract bacterial fraction DNA

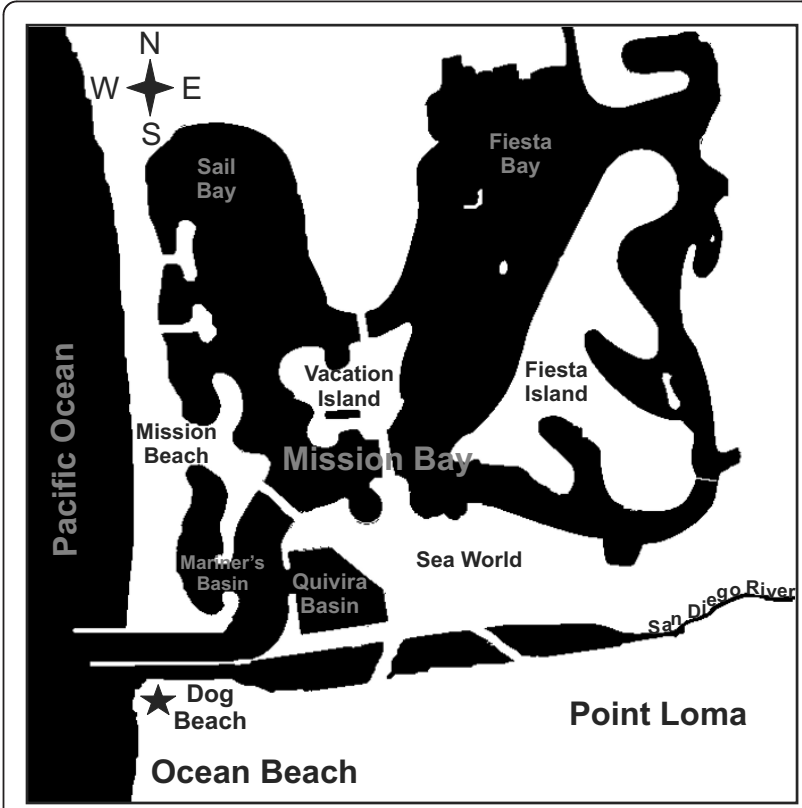

Figure 1 Map of sampling location and surrounding waterways. The Dog Beach area of Ocean Beach in San Diego, CA and surrounding waterways. Dog Beach is one of a few beaches in San Diego where people are allowed to bring their canine companions. The San Diego River and popular Mission Bay recreational waterways empty into the Pacific Ocean at this location. The black star indicates the Dog Beach area where fecal samples were gathered. 
from the canine fecal samples [26,27]. Briefly, fecal samples were suspended in 1:1 (w/v) $1 \mathrm{X}$ storage media $(\mathrm{SM})$ buffer in a $50 \mathrm{ml}$ conical vial and mixed overnight on an orbital shaker set at $100 \mathrm{rpm}$ [27]. The samples were then centrifuged at $11,000 \times g$ to pellet the biosolids. The supernatant was then filtered through a $0.2 \mu \mathrm{m}$ Sterivex ${ }^{\circledR}$ filter to capture the bacteria. The filter was then aseptically removed from its housing and DNA was extracted from the bacteria trapped on the filter using the MoBio UltraClean Soil DNA kit (Carlsbad, CA) maximum yield protocol.

\section{Exotoxin and 16S rRNA gene PCRs and sequencing of PCR products}

Exotoxin-specific PCR was performed on the total and bacterial fraction DNA of the canine fecal samples. The primers and PCR conditions used in this study are as described previously [26]. Exotoxin-specific and $16 \mathrm{~S}$ rRNA gene colony PCRs were performed on 89 canine fecal bacterial isolates, as described previously [26]. Five microliters of the bacterial isolate suspension cultivated from the canine feces was used as template in the PCRs. To control against contamination by PCR products, amplification and all subsequent downstream procedures were carried out in an entirely separate laboratory in a separate building from where DNA extraction and PCR assay set up procedures were performed. Separate and dedicated equipment and reagents were maintained in each laboratory. Also a negative control was included in each PCR assay performed.

The stx and 16S rRNA gene PCR products from the canine fecal bacterial isolates were gel purified using the MoBio UltraClean GelSpin kit (Carlsbad, CA) to prepare for sequencing. Sequencing of the stx and 16S rRNA gene PCR products was performed by the SDSU MicroChemical Core facility using the ABI Prism ${ }^{\circledR} 3100$ capillary electrophoresis DNA sequencer.

Cultivation of bacterial isolates from canine fecal samples Canine fecal samples were re-suspended 1:1 (w/v) in 1X $\mathrm{SM}$ buffer in a $50 \mathrm{ml}$ conical vial. The samples were mixed overnight on an orbital shaker set at $100 \mathrm{rpm}$. The samples were then centrifuged at $11,000 \times g$ to pellet the biosolids. One hundred microliters of serial 10-fold dilutions of the supernatant were plated onto Luria Bertani (LB) agar plates to allow for isolation of single colonies. All plates were incubated at room temperature for 2-3 days until colonies were visible. Isolates were then subcultured into 96-well plates containing $150 \mu \mathrm{L}$ LB broth with $15 \%$ glycerol. These sub-cultured isolates were then grown for another 2-3 days with aeration. Isolates were stored in the 96-well plates at $4^{\circ} \mathrm{C}$ until tested in the exotoxin-specific and $16 \mathrm{~S}$ rRNA gene PCRs. Isolates were then placed at $-80^{\circ} \mathrm{C}$ for permanent storage.

\section{Bioinformatic analyses of stx and 16S rRNA gene sequences}

The stx PCR product sequences were identified by BLASTN alignment against the GenBank non-redundant nucleotide database [28,29]. The $16 \mathrm{~S}$ rRNA gene sequences were de-replicated using FastGroup II [30]. The representative $16 \mathrm{~S}$ rRNA gene FastGroup II sequences were used for the subsequent phylogenetic analyses. The $16 \mathrm{~S}$ rRNA gene sequences were identified taxonomically by using the Ribosomal Database Project (RDP) Classifier [31] and phylogenetic trees were also generated as a means of classifying the canine fecal bacterial isolates. The stx sequences were also grouped according to the FastGroup II analyses and analyzed phylogenetically to visualize their relationship to other known stx sequences. The DNAPARS DNA parsimony program was used to generate the phylogenetic trees of both the $16 \mathrm{~S}$ rRNA gene and stx PCR product sequences [32]. The bootstrap method with 1000 replicates, 989 steps, at 580 sites was performed for the $16 \mathrm{~S}$ rRNA gene sequence analyses. For the stx gene sequence analyses, the bootstrap method with 1000 replicates, 2822 steps, at 1278 sites was performed. Consensus trees were used to represent the data and those groups at a relative frequency less than $10 \%$ were not shown.

\section{Results}

Shiga toxin (stx) gene detected in total and bacterial fraction DNA and bacterial isolate cultivated from canine feces

Twenty canine fecal samples were gathered from the shoreline at the Ocean Beach Dog Beach in San Diego, California. Total and bacterial fraction DNA was extracted from the fecal samples and screened for the stx gene by $s t x$-specific PCR. The stx gene was detected in both the total and bacterial fraction DNA (Figure 2A and $2 \mathrm{~B}$, respectively). Bacterial isolates were cultivated from the canine fecal sample where the stx gene was detected. Eighty nine bacterial isolates were screened for the stx gene and it was detected in five of these isolates (Figure 2C). No PCR products were detected in the negative controls.

\section{Phylogenetic analyses of stx PCR product}

The stx PCR products generated from the three FastGroup II representative canine fecal bacterial isolate groups were purified and sequenced (designated group 1-3, see $16 \mathrm{~S}$ rRNA gene sequence results below for description). A BLASTN alignment of the sequences to the GenBank non-redundant nucleotide database was performed and they were confirmed to be the stx gene. A phylogenetic analysis of the $s t x$ sequences was also performed $[28,29]$. The three representative stx gene sequences were grouped with known E. coli O157:H7 stx gene sequences (Figure 3). 


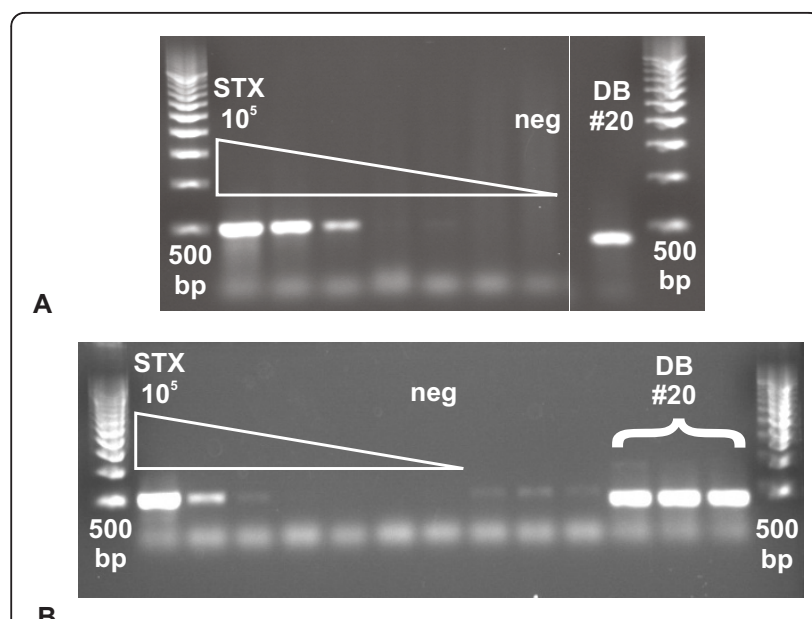

B

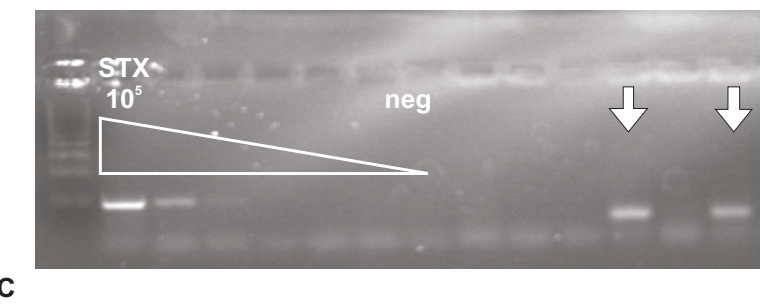

Figure 2 Agarose gel picture of stx-specific PCR on canine fecal DNA and canine fecal isolates. A) Initial stx-specific PCR screening of DNA extracted from canine fecal samples, B) stx-specific PCR on bacterial DNA extracted from canine fecal samples $(n=3,10 \mu l$ and $20 \mu \mathrm{l}$ loaded), and C) stx-specific PCR showing two of the five positive results from the cultured bacterial isolates. White arrows indicate the stx-positive isolates. White triangle is stx standard curve from $10 E 5$ copies $\mathrm{ml}^{-1}$ to one copy $\mathrm{ml}^{-1}$, neg = negative control, DB \#20 = Dog Beach fecal sample \#20, 500 bp $=500$ base pair DNA ladder. Negative controls consistently had no detectable PCR products.

The stx gene from groups 2 and 3 clustered together. The bootstrap values for these groupings were greater than 74 .

\section{Canine fecal bacterial isolates carrying stx gene identified} as Enterococcus

The $s t x$ gene was detected in five of the 89 bacterial isolates screened by stx-specific PCR (designated G516S. STX, H616S.STX, H716S.STX, H816S.STX, H916S. STX). A 16S rRNA gene PCR was performed on the five bacterial isolates. The resulting PCR product was purified and sequenced. The five $16 \mathrm{~S}$ rRNA gene sequences were de-replicated using FastGroup II [30] and three distinct groups were identified (group 1 = G516S.STX; group 2 = H716S.STX, H816S.STX; group $3=$ H616S. STX, H916S.STX). Representative sequences from these groups were utilized to molecularly identify the canine fecal bacterial isolates. First, the $16 \mathrm{~S}$ rRNA gene sequences were identified taxonomically by using the Ribosomal Database Project (RDP) Classifier [31]. The RDP Classifier identified the three groups as belonging to the genus Enterococcus. To confirm this classification, a phylogenetic tree was generated (Figure 4). These phylogenetic analyses confirmed that the canine fecal isolates belonged to the genus Enterococcus.

\section{Conclusions}

The beaches of San Diego, California are a popular destination for residents and tourists alike. Some of these beaches are designated as canine-friendly where people and their canine pets are allowed to enjoy the recreational waters together. One of these beaches is the Ocean Beach Dog Beach. This location is unique because not only is it a dog beach, but it is also an outlet into the Pacific Ocean for the San Diego River and the Mission Bay recreational waterways. As a result, this area is impacted by pollution and often closed for exceeding bacterial standards levels $[1,2]$. Important for water quality monitoring agencies is keeping the possibility of spread of infectious disease from bacteria and viruses relatively low. A paramount concern is pollution by human and animal waste because it carries disease-causing bacteria and viruses. With the close interaction of humans and animals at locations like Dog Beach, a potential reservoir for novel infectious disease pathogens may exist.

Exactly what kind of impact does the close interaction of humans and canines have on this environment and the microorganisms inhabiting it? Bacteria and their viruses (bacteriophage) are abundant in aquatic environments [33-37] and genetic exchange between these microorganisms occurs at a high frequency [25]. Some bacteriophage carry exotoxin genes that, when integrated into the bacterial chromosome, can transduce an avirulent bacterium to virulence. The influx of human- and animal-associated microorganisms to this environment may be providing a selective niche for the evolution of novel pathogens.

Many enteropathogenic microorganisms are found in animal feces and examples of the bacterial pathogens include Salmonella spp., Shigella spp., Vibrio cholera, and Escherichia coli. Certain strains of Shigella spp. and E. coli cause gastrointestinal illnesses and can carry the bacteriophage-encoded shiga toxin (stx) gene [38]. We hypothesized that bacteria cultivated from canine fecal samples collected from the Ocean Beach Dog Beach may contain the stx gene normally found in the fecal Shigella spp. or E. coli.

Canine fecal samples were collected from the shoreline of the Ocean Beach Dog Beach in San Diego, California and screened for the stx gene. The stx gene was detected in one of the 20 fecal samples. Bacterial isolates were cultivated from this fecal sample and the stx gene was detected in five of these isolates. Phylogenetic analyses of the 16S rRNA gene sequences from these isolates determined these isolates belonged to the Enterococcus genus and not the typical E. coli or Shigella spp. host. These 


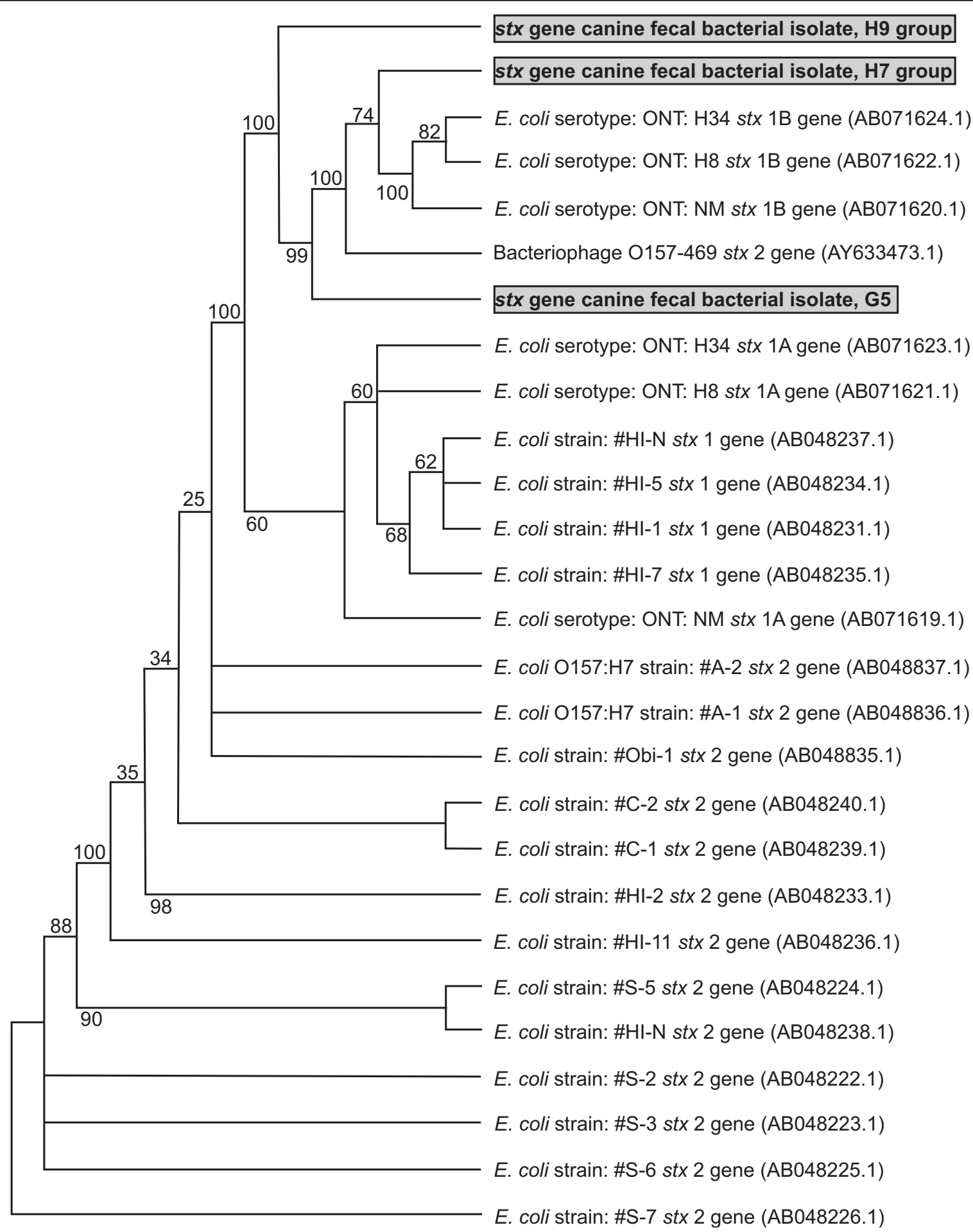

Figure 3 Phylogenetic analysis of stx gene PCR product of total DNA. The DNAPARS DNA parsimony program was used to generate the phylogenetic trees of the representative stx PCR product sequences [32]. The bootstrap method with 1000 replicates, 2822 steps, at 1278 sites was performed. The consensus tree is shown. The three canine fecal bacterial isolate groups are indicated by the gray boxes. GenBank accession numbers are indicated in parentheses. 


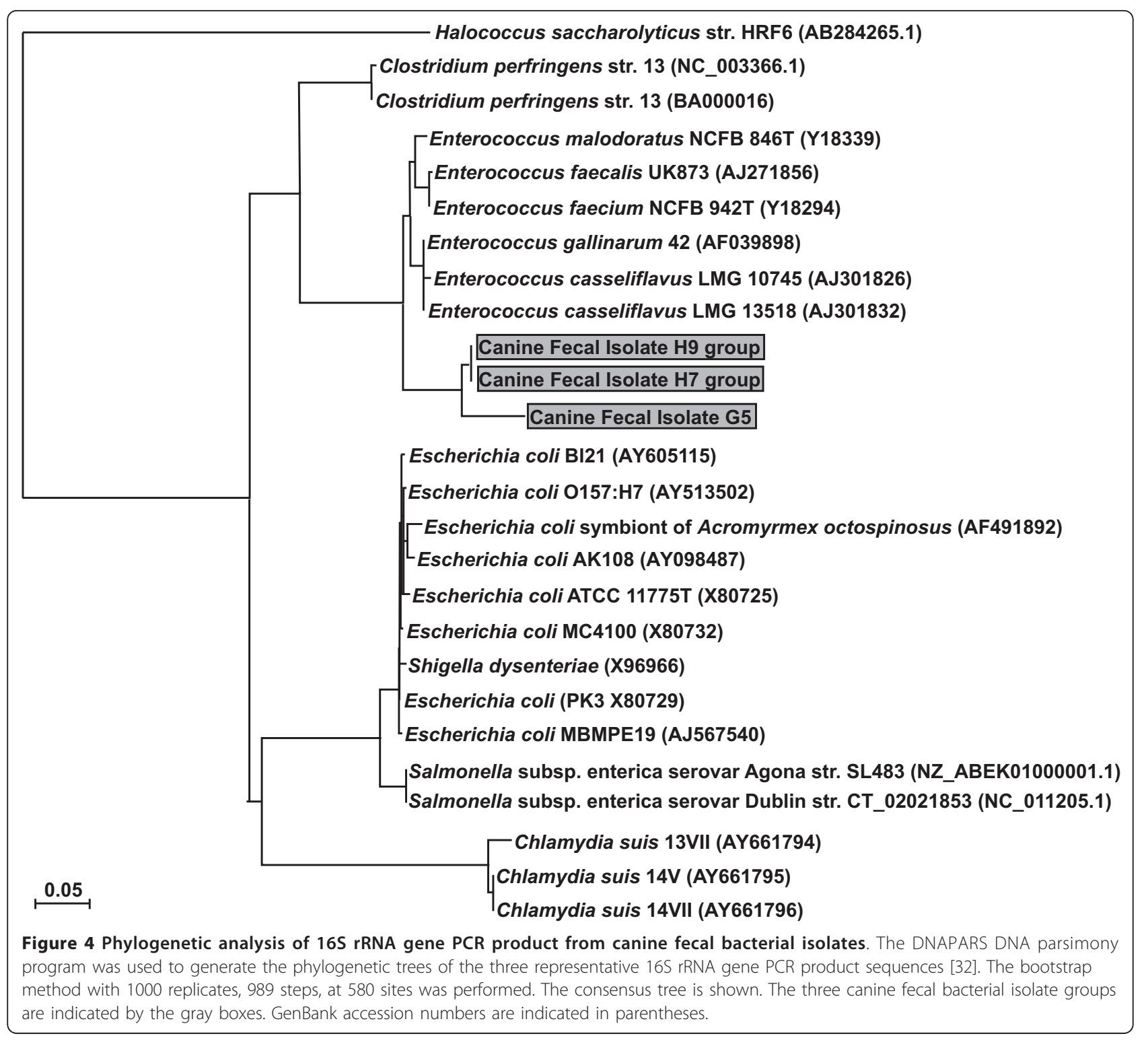

results suggest a unique horizontal gene transfer event has occurred. One possibility for this event is that bacteriophage carrying the $s t x$ gene has a broad host range that allows it to infect Enterococcus spp. as well as E. coli and Shigella spp., or a genetic exchange has occurred between the $s t x$-carrying-bacteriophage and a bacteriophage that infects Enterococcus spp.

Our results suggest that canine feces may be a reservoir for the bacteriophage-encoded stx gene and that this gene can be transferred to new bacterial hosts. This has implications in the development of new infectious diseases. A further, in depth assessment of the genomics of the bacterial and bacteriophage communities present in these recreational waterways and the potential fecal sources of contamination would shed more light on the extent to which horizontal gene transfer is occurring in these environments. Our study presents a first step in examining the reservoir of bacteriophage-encoded virulence genes present in animal waste and the potential impact exchange of these genes between atypical hosts may be having on the evolution of novel human pathogens.

\section{Acknowledgements}

This research was supported, in part, by NCl grants \#U54CA132384 and \#1U54CA132379.

\section{Author details}

${ }^{1}$ San Diego State University 5500 Campanile Drive San Diego, California 92182-4614 USA. ${ }^{2}$ Center for Microbial Sciences 5500 Campanile Drive San Diego, California 92182-4614 USA. 


\section{Authors' contributions}

VC conceived of the study, designed the experiment and protocols, collected fecal samples, processed fecal samples, analyzed data, and drafted the manuscript. GS conceived of the study, collected fecal samples, processed fecal samples, executed PCR assays, performed culturing assays, and collected data. BRM performed the bioinformatic and phylogenetic analyses. JA processed fecal samples, managed cultured isolates, and executed PCR assays. SM provided advice in experimental design and reviewed and edited the manuscript. All authors read and approved the final manuscript.

\section{Competing interests}

The authors declare that they have no competing interests.

Received: 18 June 2011 Accepted: 7 July 2011 Published: 7 July 2011

\section{References}

1. McPherson M: 2006 San Diego County Beach Closures and Advisory Report. In San Diego County Beach Closures and Advisory Report. Edited by: McPherson M. San Diego: Department of Environmental Health and The Ocean and Bay Recreational Water Program; 2006:

2. McPherson M: Beach water quality contamination events and days posted for beaches within San Diego County, California, USA. San Diego: Department of Environmental Health and The Ocean and Bays Recreational Water Program; 20066.

3. Atlas RM, Bartha R: Microbial Ecology: Fundamentals and Applications. Menlo Park: Benjamin/Cummings Science Publishing; 41998.

4. Griffin DW, Gibson CJ, Lipp EK, Riley K, Paul JH, Rose JB: Detection of viral pathogens by reverse transcriptase PCR and of microbial indicators by standard methods in the canals of the Florida Keys. Appl Environ Microbiol 1999, 65(9):4118-4125.

5. Griffin DW, Donaldson KA, Paul JH, Rose JB: Pathogenic human viruses in coastal waters. Clin Microbiol Rev 2003, 16(1):129-+.

6. Hot D, Legeay O, Jacques J, Gantzer C, Caudrelier Y, Guyard K, Lange M, Andreoletti L: Detection of somatic phages, infectious enteroviruses and enterovirus genomes as indicators of human enteric viral pollution in surface water. Water Res 2003, 37(19):4703-4710.

7. Gersberg RM, Rose MA, Robles-Sikisaka R, Dhar AK: Quantitative detection of hepatitis A virus and enteroviruses near the United States-Mexico border and correlation with levels of fecal indicator bacteria. Appl Environ Microbiol 2006, 72(12):7438-7444.

8. Lipp EK, Futch IC, Griffin DW: Analysis of multiple enteric viral targets as sewage markers in coral reefs. Mar Pollut Bull 2007, 54(12):1897-1902.

9. Leclerc H, Schwartzbrod L, Dei-Cas E: Microbial Agents Associated with Waterborne Diseases. Crit Rev Microbiol 2002, 28(4):371-409.

10. Rose JB, Huffman DE, Riley K, Farrah SR, Lukasik JO, Hamann CL: Reduction of enteric microorganisms at the Upper Occoquan Sewage Authority Water Reclamation Plant. Water Environment Research 2001, 73(6):711-720.

11. Ottoson J, Stenstrom TA: Faecal contamination of greywater and associated microbial risks. Water Res 2003, 37(3):645-655.

12. Guzman C, Jofre J, Montemayor M, Lucena F: Occurrence and levels of indicators and selected pathogens in different sludges and biosolids. J Appl Microbiol 2007, 103:2420-2429.

13. Graczyk TK, Majewska AC, Schwab KJ: The role of birds in dissemination of human waterborne enteropathogens. Trends in Parasitology 2008, 24(2):55-59.

14. Recreational Water Quality Information. San Diego: San Diego County Department of Environmental Health; 2008.

15. Wade TJ, Pai N, Eisenberg JNS, Colford JM: Do US Environmental Protection Agency water quality guidelines for recreational waters prevent gastrointestinal illness? A systematic review and meta-analysis. Environ Health Perspect 2003, 111(8):1102-1109.

16. Brownell MJ, Harwood VJ, Kurz RC, McQuaig SM, Lukasik J, Scott TM: Confirmation of putative stormwater impact on water quality at a Florida beach by microbial source tracking methods and structure of indicator organism populations. Water Res 2007, 41(16):3747-3757.

17. Bej AK, McCarty SC, Atlas RM: Detection of coliform bacteria and Escherichia coli by multiplex polymerase chain reaction: comparison with defined substrate and plating methods for water quality monitoring. Appl Environ Microbiol 1991, 57(8):2429-2432.
18. Blackwood AD, Gregory JB, Noble RT: Determination of the quantitative relationship between indicator bacteria and viral pathogens in recreational waters using quantitative PCR. Abstracts of the General Meeting of the American Society for Microbiology 2003, Q-427.

19. Jiang SC, Chu W: PCR detection of pathogenic viruses in southern California urban rivers. J Appl Microbiol 2004, 97(1):17-28.

20. Freeman BJ: Studies on the virulence of bacteriophage-infected strains of Corynebacterium diphtheriae. J Bacteriol 1951, 61:675-688.

21. Groman NB: The relation of bacteriophage to the change of Corynebacterium diphtheriae from avirulence to virulence. Science 1953, 117:297-299.

22. Waldor MK, Mekalanos JJ: Lysogenic conversion by a filamentous phage encoding cholera toxin. Science 1996, 272:1910-1914.

23. Acheson DWK, Reidl J, Zhang X, Keusch GT, Mekalanos JJ, Waldor MK: In vivo transduction with Shiga toxin 1-encoding phage. Infect Immun 1998, 66(9):4496-4498.

24. Betley MJ, Mekalanos JJ: Staphylococcal enterotoxin A is encoded by phage. Science 1985, 229:185-187

25. Bushman F: Lateral DNA Transfer. Cold Spring Harbor: Cold Spring Harbor Laboratory; 2002.

26. Casas V, Miyake J, Balsley H, Roark J, Telles S, Leeds S, Zurita I, Breitbart M, Azam F, Bartlett D, Azam F, Rohwer F: Widespread occurrence of phageencoded exotoxin genes in terrestrial and aquatic environments in Southern California. FEMS Microbiol Lett 2006, 261:141-149.

27. Casas V, Rohwer F: Phage Metagenomics. Methods Enzymol 2007, 421:259-268.

28. Benson DA, Karsch-Mizrachi I, Lipman DJ, Ostell J, Rapp BA, Wheeler DL GenBank. Nucl Acids Res 2000, 28(1):15-18.

29. Altschul SF, Gish W, Miller W, Myers EW, Lipman DJ: Basic local alignment search tool. J Mol Biol 1990, 215(3):403-410.

30. Yu Y, Breitbart M, McNairnie P, Rohwer F: FastGroupll: A web-based bioinformatics platform for analyses of large 16S rDNA libraries. BMC Bioinformatics 2006, 7(1):57.

31. Wang Q, Garrity GM, Tiedje JM, Cole JR: Naïve Bayesian Classifier for Rapid Assignment of rRNA Sequences into the New Bacterial Taxonomy. Appl Environ Microbiol 2007, 73(16):5261-5267.

32. Felsenstein J: DNAPARS-DNA parsimony program, v. 3.5c. University of Washington: University of Washington: 3.5c 1993.

33. Hewson I, O'Neil JM, Fuhrman JA, Dennison WC: Virus-like particle distribution and abundance in sediments and overlying waters along eutrophication gradients in two subtropical estuaries. Limnology and Oceanography 2001, 46(7):1734-1746.

34. Bergh O, Borsheim KY, Bratbak G, Heldal M: High abundance of viruses found in aquatic environments. Nature 1989, 340:467-468.

35. Danovaro R, Dell'Anno A, Trucco A, Serresi M, Vanucci S: Determination of virus abundance in marine sediments. Appl Environ Microbiol 2001 67(3):1384-1387.

36. Maranger R, Bird DF: Viral abundance in aquatic systems: a comparison between marine and fresh water. Mar Ecol Prog Ser 1995, 121:217-226.

37. Maranger R, Bird DF: High concentrations of viruses in the sediments of Lac Gilbert, Quebec. Microb Ecol 1996, 31:141-151.

38. Murray PR, Rosenthal KS, Kobayashi GS, Pfaller MA: Medical Microbiology. St. Louis: Mosby, Inc ii 42002.

doi:10.1186/1757-4749-3-10

Cite this article as: Casas et al: Bacteriophage-encoded shiga toxin gene in atypical bacterial host. Gut Pathogens 2011 3:10. 